\title{
Synthesis
}

\section{Resilience Thinking and a Decision-Analytic Approach to Conservation: Strange Bedfellows or Essential Partners?}

\author{
$\underline{F r e d ~ A . ~ J o h n s o n ~}^{1}, \underline{B}$ Ken Williams ${ }^{2}$ and James D. Nichols ${ }^{1}$
}

\begin{abstract}
There has been some tendency to view decision science and resilience theory as opposing approaches, or at least as contending perspectives, for natural resource management. Resilience proponents have been especially critical of optimization in decision science, at least for those cases where it is focused on the aggressive pursuit of efficiency. In general, optimization of resource systems is held to reduce spatial, temporal, or organizational heterogeneity that would otherwise limit efficiency, leading to homogenization of a system and making it less able to cope with unexpected changes or disturbances. For their part, decision analysts have been critical of resilience proponents for not providing much practical advice to decision makers. We believe a key source of tension between resilience thinking and application of decision science is the pursuit of efficiency in the latter (i.e., choosing the "best" management action or strategy option to maximize productivity of one or few resource components), vs. a desire in the former to keep options open (i.e., maintaining and enhancing diversity). It seems obvious, however, that with managed natural systems, there must be a principle by which to guide decision making, which at a minimum allows for a comparison of projected outcomes associated with decision alternatives. This is true even if the primary concern of decision making is the preservation of system resilience. We describe how a careful framing of conservation problems, especially in terms of management objectives and predictive models, can help reduce the purported tension between resilience thinking and decision analysis. In particular, objective setting in conservation problems needs to be more attuned to the dynamics of ecological systems and to the possibility of deep uncertainties that underlie the risk of unintended, if not irreversible, outcomes. Resilience thinking also leads to the suggestion that model development should focus more on process rather than pattern, on multiple scales of influence, and on phenomena that can create alternative stability regimes. Although we acknowledge the inherent difficulties in modeling ecological processes, we stress that formulation of useful models need not depend on a thorough mechanistic understanding or precise parameterization, assuming that uncertainty is acknowledged and treated in a systematic manner.
\end{abstract}

Key Words: adaptive management; alternative stability regime; biodiversity; conservation; decision analysis; decision science; dynamic decisions; modeling; optimization; resilience; robust decision making; systems; uncertainty

\section{INTRODUCTION}

Conservationists are under increasing pressure to demonstrate that their activities are cost effective and achieving intended ecological and social benefits (Possingham 2001, Keene and Pullin 2011). Demonstrating this effectiveness is proving to be quite challenging, however. Valuing biodiversity benefits and costs can be exceedingly difficult, success with most conservation practices is highly uncertain, and threats to biodiversity are growing faster than the resources needed to address them. The application of decision science is increasingly seen as a means of coping with these realities, focused as it is on explicit recognition of risk and the valuation of consequences (Gregory et al. 2012). Described by Keeney (1982) as "a formalization of common sense for decision problems which are too complex for informal use of common sense," decision analysis provides a logical framework for systematic thinking about decision making (Clemen 1996).

Decision analysis has long been used in business and government decision making (Keefer et al. 2004), but its application to problems in natural resource management (NRM) has mostly occurred over the last two decades (Huang et al. 2011). Approaches vary considerably, but they all involve: (1) properly formulating the decision problem; (2) specifying feasible alternative actions and predicting their consequences; and (3) selecting criteria for evaluating the (possibly uncertain) outcomes of the decision alternatives (Tonn et al. 2000). Modern methods, such as multicriteria decision analysis, emphasize fundamental values and multiple-objective trade-offs that are inherent in NRM (Keeney 1992, Arvai et al. 2001). An emphasis on values reflects the reality that scientific predictions (no matter how certain) will not necessarily lead to consensus, and decision makers need to understand the extent of conflicts about predicted outcomes and how those outcomes are valued (Lee 1993). Decision analytic approaches that account for outcomes and values are now widely used in conservation, with a formal structuring of decision problems that allows for conflict in values among stakeholders (Kiker et al. 2005, Mendoza and Martins 2006, Hajkowicz and Collins 2007, Huang et al. 2011).

Accompanying the broader application of decision science has been the growing popularity of adaptive resource management 
(Walters 1986, Williams 2011a). The core principles in adaptive management of managing to learn and learning to manage are so self-evident that virtually all resource professionals today view adaptive management as a creed of sensible resource management. Yet, reported success stories are rare, and field examples often fail to meet one or more basic requirements of adaptive management (Moir and Block 2001, Schreiber et al. 2004, Susskind et al. 2010). The barriers to implementation, learning, and adaptation are well documented, and concerns have been raised about the applicability of adaptive management to "wicked problems" in resource conservation (Gunderson et al. 2008). On the whole, Kai Lee's observation that "adaptive management has been more influential, so far, as an idea than as a practical means of gaining insight into the behavior of ecosystems utilized and inhabited by humans" (Lee 1999) is as relevant today as it was over a decade ago.

Despite these difficulties, we believe adaptive management and, more generally, decision science are helping to change the culture of conservation and thus are having an impact far broader than any improvements in resource conditions that may or may not have been achieved in particular applications. The popularity of these concepts has made it acceptable (even fashionable) to acknowledge uncertainty and its consequences for resource management. Opportunities to learn through management are being explored, if not yet routinely exploited, and a greater focus on uncertainty is producing a revolution in the application of decision science to inform conservation planning (Burgman 2005, Conroy and Carroll 2009, Moilanen et al. 2009).

Having been directly involved in NRM throughout most of our careers, we are all too familiar with the way in which conservation decisions are often made-i.e., using intuition as a substitute for systematic analysis that involves problem formulation, objective setting, identification of alternative actions, explicit predictions, and the recognition of key sources of uncertainty. Although decision analysis is not a panacea for all the difficult conservation problems we face, we believe that a decision-analytic framework can be useful for systematically exploring values and potential outcomes for a great many problems. Such a framework can help to focus the compilation and application of existing information, lend transparency and repeatability to the process, and provide a means to identify key uncertainties and how they might be reduced through learning-oriented management. Whatever the particular details of a decision problem, the complementary processes of predicting and valuing outcomes seem fundamental to the practice of conservation.

It is noteworthy that not everyone concerned with the conservation of natural resources agrees about the utility of decision analysis (Carpenter 2002, Walker et al. 2002, Polasky et al. 2011a). Conservation problems increasingly have a cross-scale nature (both in space and time) that can greatly complicate the analysis, with global changes having important local implications and vice versa (Holling 2001). The concept of a single decision maker who optimizes a finite set of utilities is often seen as arbitrary and inappropriate (Berkes 2010), and many believe that top-down control, with its focus on efficiency at the expense of natural variability, is unlikely to deliver sustainable ecosystem goods and services (Holling and Meffe 1996). The unrealistic assumption of equilibrium in natural systems, the challenging problem of specifying possible system states and associated probabilities, and the possibility of thresholds and alternative stable states, have led to serious questions about the utility of classic decisionanalytic approaches (Holling 1973, Ludwig et al. 1997, Gunderson 1999, Carpenter 2002, Gunderson et al. 2002, Walker et al. 2002, Peterson et al. 2003a, Polasky et al. 2011a).

A growing recognition of these complexities has helped spur the rise of "resilience thinking" (Walker and Salt 2006) in NRM (Chapin et al. 2009). Resilience is characterized as the disturbance that can be absorbed without shifting the system to an alternative stability regime (or "domain of attraction") (Holling 1973), or the magnitude of disturbance a system can absorb while still retaining essentially the same function, structure, identity, and feedbacks (Walker et al. 2004). Linked ecological and social systems are seen as complex adaptive systems, in which emergent behaviors result from the presence of a diverse set of system components (e.g., species, stakeholders), nonlinear interactions among components (for example, competition, politics), and autonomous selection processes (e.g., natural selection, courts) (Levin 1999). Complex adaptive systems have an evolving nature that is characterized by ongoing cycles of growth, accumulation, restructuring, and renewal (Gunderson et al. 1995). The term "panarchy" is used to describe a nested arrangement of such adaptive cycles across space and time, such that changes in the dynamics at one scale can cascade to impact system dynamics at other scales (Holling 2001). One of the most relevant concepts in resilience theory for conservation is the possibility that social-ecological systems can exist in alternative stability regimes - some of which might be quite undesirable from a human perspective (e.g., the replacement of semi-arid grasslands by desert).

There has been some tendency to view decision science and resilience theory as opposing approaches, or at least as contending perspectives, for conservation (Walker et al. 2002, Fischer et al. 2009, McFadden et al. 2011, Polasky et al. 2011a). Some authors have argued that, in light of resilience theory, optimization-based planning with its focus on maximizing efficiency is "a large part of the problem, not the solution" (Walker and Salt 2006) for NRM (Holling and Meffe 1996, Linkov et al. 2006). We believe that a difficulty with such a critique is that it fails to account for systems subjected to human interventions and the imperative to manage them. It 
seems obvious that with managed natural systems there must be a principle by which to guide decision making, which at a minimum allows for a comparison among decision alternatives. If decision making in conservation is to be based on more than intuition or chance, the decision process must include some criterion for measuring the relative value of conservation alternatives and a mechanism for selecting among them. This is true even if the primary concern of decision making is the preservation of system resilience.

Our goal here is to explore some of the points of tension between resilience thinking and a decision-analytic approach, and to suggest some implications of resilience thinking for a decision-analytic approach to conservation. We focus on the conservation of biodiversity, recognizing that it is widely seen as an important contributor to resilience in social-ecological systems (Peterson et al. 1998, Tilman 1999, Naeem 2002, Elmqvist et al. 2003, Hooper et al. 2005, Hector and Wilby 2009). We first examine some of the criticisms leveled by adherents of each perspective that have tended to isolate the two camps from each other. We then describe how a careful framing of conservation problems, particularly in terms of management objectives and predictive models, can help reduce the purported tension between resilience thinking and decision analysis.

\section{RESILIENCE-BASED AND DECISION-ANALYTIC PERSPECTIVES}

Here, we focus in more detail on the purported conflict between resilience-based and decision-analytical approaches to NRM. By "decision analysis" or "decision science," we mean a methodology for framing a decision problem to make it amenable to formal analysis, and for identifying the alternative choice(s) that is (are) most likely to meet the decision maker's objectives. Therefore, decision analysis must integrate what the decision maker values, what the available options are, and what the consequences of those options are likely to be (Skinner 2009). Viewed broadly, however, decision analysis has a number of components and may make use of various decision-support tools that do not directly pertain to the process of selecting an action and hence making a decision. For the purposes of this paper, we do not consider this broad view, instead focusing on decision-analytic methods that include the process of optimization, a primary target of criticism by some proponents of resilience thinking. Thus, our use of the term decision analysis includes the step of deciding which member of a set of available actions to implement.

Although we endeavored to be accurate in the following descriptions of resilience-based and decision-analytic perspectives, we acknowledge the biases we hold as proponents of decision analysis. And to be fair, we note that resilience thinkers have only rarely criticized the application of decision science per se; more often, the issue of real concern is "how" decision science is applied. Our objective here is simply to provide some background and context for thinking about how to better integrate these two perspectives on resource management.

\section{A Resilience-Based Critique of Conventional Natural Resource Management}

From a resilience-based perspective, much of the criticism has focused on historic patterns of resource development, particularly as influenced by large-scale social and technological trends (Ludwig 2001). Critics argue that the prevailing paradigm for resource development has led to the over-commodification of nature, whereby natural resources only have value to the extent that they can serve as goods for human satisfaction or utility (Freese 1998, Berkes 2010). Utilitarian goods are seen as marketable and largely free for the taking. By implication, ecosystem goods and services that are not marketable are assumed to be valueless. Thus, this criticism focuses on the narrow objectives that have been used historically in some decision-analytic approaches to management, and the need to broaden them to include a wider suite of ecosystem goods and services.

In general, proponents of resilience thinking have argued that that there are no manifest boundaries for understanding and managing social-ecological systems and addressing their threats (Levin 1992). Decision analysts are thought to frame problems too narrowly in an attempt to make them more analytically tractable (Carpenter et al. 2009). This simplification often ignores cross-scale effects that can produce unexpected behaviors as well as occasionally bad, and sometimes irreversible, outcomes (Ascher 2001). Also, many important conservation problems are of sufficient scope and scale that their remediation will have collateral effects on other cultural, economic, or aesthetic values. These values are likely to conflict to some degree, and various interest groups tend to jostle for power over the decision-making process. A large number of conservation challenges do not fit into the context of a single decision maker optimizing a finite and unambiguously weighted set of values. Indeed, on all but the smallest scales, there usually are multiple decision makers acting more or less independently in pursuit of their own agendas.

Resilience proponents have been especially critical of optimization, at least for those cases where it is focused on the aggressive pursuit of efficiency (Walker and Salt 2006, Norberg et al. 2008). In general, optimization (and more generally, modeling) of resource systems is held to reduce spatial, temporal, or organizational heterogeneity that would otherwise limit efficiency, leading to homogenization of a system and reduced capacity to cope with unexpected changes or disturbances (e.g., crop monocultures or undiversified investment portfolios) (Meyer 1976, Holling and Meffe 1996). It is further asserted that optimization increases the risk of 
regime change by narrowing the basin of attraction of a desirable domain (i.e., reducing resilience) (Peterson et al. 1998, Levin 1999, Walker and Salt 2006). It seems, then, that a key source of tension between resilience thinking and application of decision science is the pursuit of efficiency in the latter (i.e., choosing the "best" management action or strategy to maximize productivity of one or few resource components), vs. a desire in the former to keep options open (i.e., maintaining and enhancing diversity) (Norberg et al. 2008). Whether this tension can be reconciled is perhaps the most pressing question facing those who understand and appreciate the value of resilience thinking, yet also understand the necessity of helping resource managers make difficult decisions.

Also at the forefront of resilience thinking has been the recognition that resources can be exploited beyond their renewal capacity and that unfettered access can lead to resource collapse (Hardin 1968, Clark 1971, Clark and Munro 1978). In the course of resource development, the gradual recognition of resource limitation has fostered the rise of a managerial class whose purpose is not only to regulate access to the commons, but also to ensure that natural resources are used efficiently (e.g., via the concept of maximum sustainable yield or some other, less formal, concept) (Ludwig et al. 1993, Holling and Meffe 1996, Ludwig 2001). This approach reinforces the philosophy that nature is to be used for the betterment of mankind and that humans stand apart from the systems they are attempting to manage. And until recently, the study of the management of ecological systems was preoccupied with equilibrium conditions and management actions that are intended to stabilize resource states at their most productive level (Holling 1973). The argument is that the science of resource management has been primarily reductionist, and generally has failed to recognize the uncertainties and nonlinear behaviors that undermine equilibria and lead to alternative stability regimes and hysteresis (Ludwig 2001). These criticisms generally focus on the inadequacies of models used to predict system behaviors and responses to management.

Resilience thinkers seem by implication to question the need to predict outcomes attendant to alternative decision choices. Predictions are held to require more data than is likely to be available for many, if not most, conservation problems (Polasky et al. 2011a). And even if empirical information is available, decision makers run the risk that the dynamics of the system of interest are changing, so that the past is no longer prologue (Carpenter et al. 2009). This can be particularly problematic given the increasing scale and pace of global and human-induced change. To make matters worse, resilience theory postulates that social-ecological systems are complex adaptive systems that are inherently unpredictable, with nonlinear and cross-scale interactions producing a level of uncertainty that is ever present and may be largely unknowable. These criticisms are also focused on the inadequacies of models used to predict system behaviors and responses to management.

This critique of conventional NRM, which by now is well developed and widely accepted by resilience analysts (Berkes 2010), has helped motivate some important changes to the way resource-management decisions are analyzed and made. For example, it has led to environmental decision making that is more focused on the consequences of uncertainty in system behaviors and responses to management and the risk of undesirable outcomes (Hilborn and Walters 1992, Burgman 2005, Gregory et al. 2012). There is a growing emphasis on the ecological mechanisms that produce and sustain ecosystem products and services (Carpenter 2009). That ecological and social systems are linked is now broadly recognized (if not well understood), and ecologists and social scientists are working side by side to develop integrative theories for sustainable resource development (Lee 1993, Gunderson et al. 1995, Gunderson and Holling 2002, Berkes et al. 2003). Along with these developments, more pluralism in resource governance is becoming commonplace (Lebel et al. 2006, Wilson 2006, Armitage et al. 2009).

\section{A Management-Based Critique of Resilience Thinking}

For their part, decision analysts have been critical of resilience proponents for not providing much practical advice to decision makers (Berkes 2010, Polasky et al. 2011a). To be sure, there have been many resilience-based principles recommended for sound resource management, particularly in terms of understanding the links between social and ecological systems and how modes of resource governance can enhance or decrease resilience (Levin 1999, Gunderson 2000, Gunderson and Holling 2002, Berkes et al. 2003, Lebel et al. 2006, Walker and Salt 2006, Chapin et al. 2009, Berkes 2010). Guidance gets noticeably thinner, however, when it comes to a resilience-based framing of resource-decision problems, an assessment and selection of management alternatives, and the prediction, valuation, and monitoring of decision outcomes.

Although we believe resource management can benefit from an appreciation of resilience principles, a resilience-based structuring of decision problems can seem daunting. For example, a key challenge is problem framing, in which one must determine the appropriate spatial and temporal boundaries of the social-ecological system that are relevant to the decision at hand. Yet the emphasis in resilience thinking on multiple scales has tended to make problem bounding seem more difficult, if not intractable (Levin 2000, Walker et al. 2002, Fischer et al. 2009, Polasky et al. 2011a). Moreover, empirical efforts to predict or forecast management outcomes, which involve formulating dynamic models of resilience and accounting for key uncertainties, are still in their infancy (Carpenter et al. 1999, Scheffer and Carpenter 2003, Scheffer 2009). Monitoring in terms of early warning signs for critical regime shifts is receiving increased attention (Karunanithi et 
al. 2008, Biggs 2009, Scheffer et al. 2009), but learning about regime shifts in time to avert them remains a challenge. Finally, a resilience-based approach to valuing decision outcomes has barely been explored (Carpenter et al. 1999, Peterson et al. 2003a), despite the need to define utility in a way that avoids a focus on a narrow range of ecosystem goods or services that, if optimized, could erode resilience.

Another concern among decision analysts is that proponents of resilience thinking invariably advocate the use of adaptive management (Gunderson 1999, Gunderson et al. 2008, Allen et al. 2011), while providing little guidance on how to actually plan and implement it (Gregory et al. 2006, Allen and Gunderson 2011). In particular, it is important to know when adaptive management is appropriate, and that it is not suitable for all decision problems. For example, a primary impediment to decision making is often a conflict of values among stakeholders. In this situation, adaptive management may have little to offer (although see Norton (2005)), and attempts at application can seem like displacement behavior that avoids the difficult challenges of developing effective institutional and governance structures to resolve disputes over values (Susskind et al. 2010). Nor is an adaptive approach needed if the available management choices are insensitive to structural sources of uncertainty (although even here dynamic optimization may be useful). Finally, if management choices fail to discriminate among competing system models, adaptive management will not result in learning, which is an essential aspect of adaptive decision making. Decision analysis provides a systematic framework for exploring these issues, and it is difficult to imagine how adaptive management could be planned or implemented in the absence of this structure.

In conclusion, we believe resilience thinkers have not been very successful at providing practical advice to decision makers, although we also acknowledge that decision analysts have not yet done much "resilience thinking." The lack of attention to potential links between the groups needs to change if we are to narrow the gap between the framing of resource problems and our ability to solve them.

\section{IMPLICATIONS OF RESILIENCE THINKING FOR ANALYZING CONSERVATION DECISIONS}

Despite concerns about exactly how to apply resilience concepts, we believe these concepts are increasingly relevant to conservation efforts. Because our background is in a decision-analytic approach to resource management, and because this approach is intended to provide specific recommendations for decision makers, we focus here on applying resilience concepts in a decision-analytic approach to conservation.

\section{Problem Framing and the Issue of Scale}

Those concerned with resource conservation routinely face a wide variety of decision problems, including the assignment of priorities and allocation of funds, the securement of habitat through fee title and easements, the restoration or enhancement of habitat, the management of populations through stocking, translocation or take, and the design and conduct of monitoring programs. Ultimately, all of these decision problems concern "what to do, where, and when" (Wilson et al. 2007) questions that we believe can best be approached through a careful problem structuring that involves the identification of decision alternatives, outcomes, and values (Arvai et al. 2001, Possingham 2001, Wilson et al. 2006, Gregory et al. 2012). Problem framing is an essential (and often the most difficult) part of decision analysis. It is also the aspect of decision analysis that should be a primary focus of resilience thinking (Possingham and Biggs 2012).

Of particular concern in problem framing is the notion that "the decision context and the fundamental objectives that frame a decision situation must be compatible" (Keeney 1992). Thus, the decision alternatives must be sufficient to describe the ways in which objectives (values) can be achieved, and objectives must be sufficient to permit evaluation of the alternatives under consideration. This requirement highlights the central role of scale in problem framing, especially as it concerns the need to ensure that the perceived scale of the problem is matched with the scale at which conservationists (or society) can address it (Cumming et al. 2006, Carpenter 2009). Although a decision problem may have a relatively narrow focal scale for implementation of alternatives, a consideration of both smaller and larger scales may be necessary to adequately predict and value outcomes. Unfortunately, we believe that many of the discussions of scale in conservation are unfocused and wide ranging. More than anything else, decision analysis promotes contextual thinking-i.e., recognizing the precise nature of the decision problem, defining the larger ecological and social context in which it is embedded, and identifying and evaluating alternatives.

Nonetheless, an awareness of scale issues tends to make what is already a challenging conservation decision problem even more difficult. System properties observed at any particular scale reflect both the aggregation of smaller-faster processes and the constraints imposed by larger-slower processes (Holling 1992, Levin 1992, Peterson et al. 1998, Cumming and Norberg 2008). The extent to which scales other than the focal scale of the decision need to be considered explicitly has rarely been explored. As to biodiversity, resilience theory holds that it is not species richness per se that contributes to system resilience, but rather the presence of species that have overlapping functions at a particular scale, and the presence of multiple species within functional groups that operate at widely different scales (Walker 1992, Peterson et al. 1998, Levin 2000, Folke et al. 2004, Hector and Wilby 2009). Add to this complexity the fact that resource governance often operates at myriad scales (Lebel et al. 2006), and it's enough 
to make any decision analyst's head ache. Indeed, the difficulty of accounting for multiple spatial, temporal, and organizational scales of influence, while maintaining analytical tractability, is one of the key reasons that resilience thinkers have sometimes questioned the utility of decision analysis.

So what to do? First, it is important to recognize that at small focal scales the indirect or collateral effects of conservation actions on society may be inconsequential (e.g., habitat management on properties with single owners). At these scales, a reasonable focus might be on relatively fast ecological structuring processes and a few species, with a single decision maker acting on a narrowly defined set of objectives. Certainly, there will be larger-scale constraints (e.g., climate, budget, etc.), but there also will be greater opportunity (less risk) for experimenting with novel conservation approaches. The use of active adaptive management, which treats management actions as experiments, may be particularly applicable in these situations (McCarthy and Possingham 2007). The innovations discovered through such experimentation have the potential ultimately to effect positive change in management at larger scales.

At large focal scales (e.g., a watershed or landscape), analysts may need to be more conscious of both smaller-faster and larger-slower scales, functional groups of species, and conservation actions that sometimes conflict with other socioeconomic goals. In these cases, a more open and inclusive decision-making process is required, where a broader range of values and their trade-offs is considered explicitly. To be successful at these scales, conservationists must be transparent in how they account for the diverse concerns of stakeholders (through, e.g., the quantification of opportunity costs) (Naidoo et al. 2006). At larger scales, it is often impossible to identify "the" decision maker, even among conservation interests. However, an analysis that assumes a single decision maker (for example, a government agency with statutory management responsibility) can still be helpful for developing a shared perception of the problem in the eyes of diverse authorities and stakeholders (Keeney 1982).

Ultimately, what is needed is a cross-scale approach to biodiversity conservation (Levin 2000, Willis and Whittaker 2002, Whittaker et al. 2005, Sarkar et al. 2006). From an analytical perspective, a key concern is how conservation decisions can be linked across scales. For example, the harvesting (or stocking or transplanting) of organisms is routinely viewed as a sequential decision problem, in which decisions in the present affect system status and thus decisions in the future (Anderson 1975, Williams 1989). The goal of such a sequential decision process is to balance present and future values so that the conservation strategy performs well over an extended time frame. There has been some limited work focusing on this sort of temporal trade-off in biodiversity conservation (Wilson et al. 2011). Similarly, conservation decisions made over space can be linked to promote biodiversity at a variety of scales (Poiani et al. 2000), and there have been some attempts to look at decisions linked over both time and space (Meir et al. 2004). The challenge for decision analysts is to understand when links need to (or can) be treated explicitly, i.e., those occasions when multiple, linked decisions are under the control of "the" decision maker. In other cases, extraneous decisions can be treated implicitly as either noise (in the case of smaller-scale decisions) or as constraints (in the case of larger-scale decisions) relative to the focal scale of decision making.

\section{Valuing Outcomes and Setting Objectives}

The framing of a decision problem ultimately requires a means both to project and value decision outcomes. Understanding how potential decision outcomes are perceived and valued by stakeholders is key to the development of fundamental objectives, which in turn influence all other aspects of a decision analysis (Keeney 1992, Arvai et al. 2001). There are several implications of a resilience perspective for the way in which objectives of biodiversity conservation are formulated, and we turn our attention to them in this section.

Fundamental objectives for a decision problem must be represented by one or more measurable attributes that can be used to evaluate the consequences of management actions. Because biodiversity can be a complex, multivariate attribute, conservationists routinely resort to the specification of biodiversity surrogates, such as subsets of species, species aggregations, or habitat types (Margules and Pressey 2000, Sarkar and Margules 2002, Sarkar et al. 2006). Species richness has been the most widely used metric (Westphal et al. 2003, Wilson et al. 2006, 2007, 2011, Polasky et al. 2008). Some evidence suggests, however, that it is not species richness per se that enhances system resilience, but the way in which species interact with each other and with their environment (Peterson et al. 1998). The key issue is ecological process, not pattern, and pattern can be an inadequate surrogate for process. Thus, resilience-based conservation might best be focused on the maintenance of diverse functional groups with redundancy within groups, where redundancy refers to the presence of species with overlapping function but that respond to environmental variation differently (Walker 1992, 1995). An important implication is that not all species contribute equally to resilience. Lacking a full accounting of functional types, however, conservationists may have little choice but to focus on overall species diversity, based on the idea that this objective could help ensure the requisite redundancy. In any case, the challenge is to tailor the biodiversity metric(s) to the specified conservation objectives and the values they represent. As such, there can be no omnibus biodiversity metric that will be suitable for all decision-making problems in conservation. 
In addition to biodiversity benefits, both direct and indirect costs must be considered if conservation is to be cost effective (Naidoo et al. 2006, Murdoch et al. 2007, Polasky 2008). Efforts to conduct cost-benefit analyses by assigning dollar values to conservation benefits are increasing (Farber et al. 2002, Naidoo and Ricketts 2006), but they sometimes have been criticized because biodiversity values are inevitably incomplete, markets for some important values do not exist, cost considerations are inadequately addressed, and efficiency does not necessarily imply sustainability (Bishop 1993, Nunes and van den Bergh 2001). As is often the case, benefits and costs cannot be specified using the same currency (e.g., dollars) and other approaches must be used to assess the tradeoffs. One is to attempt to maximize biodiversity benefits for a fixed conservation budget (Wilson et al. 2006, Murdoch et al. 2007). Another is to minimize the costs of sustaining biodiversity at a prescribed level. Yet another is to rely on the notion of Pareto optimality (Kennedy et al. 2008). With a Pareto-efficient solution, the conservation outcome cannot be improved without a reduction in other socioeconomic values (Bishop 1993, Polasky et al. 2005, 2008). Pareto-efficient solutions can thus be used as a basis for negotiation among stakeholders with irreconcilable values (i.e., objectives and how they might be weighted).

However the benefits and costs of conservation are measured, the effectiveness of conservation efforts ultimately depends on the recognition that decision making and the systems it is designed to affect are inherently dynamic and characterized by multiple sources of uncertainty. To cope with these challenges, conservation planners are increasingly turning to the tools of dynamic optimization. Here, we provide a general framework for optimal, dynamic conservation and then explore its capacity to cope with various sources and degrees of uncertainty.

\section{System dynamics}

In general, the management of ecosystem change over time can be framed with time-specific utilities $U\left(a_{t} \mid \mathrm{x}_{t}\right)$ and transition probabilities $P\left(x_{t+1} \mid \mathrm{x}_{t}, \mathrm{a}_{t}\right)$ corresponding to a particular action $a_{t}$ and resource state $x_{t}$ at time $t$ for a time horizon that extends to time $T$, which may be infinite. Assuming the system is known and fully observed, management might focus on the aggregation of utilities through time, as in

$$
V\left(A_{t} \mid x_{t}\right)=E\left[\sum_{\tau=t}^{T} U\left(a_{\tau} \mid x_{\tau}\right) \mid x_{t}\right]
$$

In this value function $A_{t}$ represents a strategy specifying actions for each state at each time over the remainder of the timeframe, starting in state $x_{t}$ at time $t$. However utility (i.e., benefits net costs) is defined, the management challenge is to choose a strategy $A_{t}^{*}$ that maximizes $V\left(A_{t} \mid \mathrm{x}_{t}\right)$ for any initial state $x_{t}$ :

$$
\begin{aligned}
V\left[x_{t}\right] & =\max _{A_{t}} V\left(A_{t} \mid x_{t}\right) \\
& =V\left(A_{t}^{*} \mid x_{t}\right) .
\end{aligned}
$$

The value function can be written in iterative form as

$$
\begin{aligned}
V\left(A_{t} \mid x_{t}\right) & =U\left(a_{t} \mid x_{t}\right)+E\left[\sum_{\tau=t+1}^{T} U\left(a_{\tau} \mid x_{\tau}\right) \mid x_{t+1}\right] \\
& =U\left(a_{t} \mid x_{t}\right)+\sum_{x_{t+1}} P\left(x_{t+1} \mid x_{t}, a_{t}\right) V\left(A_{t+1} \mid x_{i+1}\right),
\end{aligned}
$$

which expresses value in terms of current and future accumulations of utility, with an optimal value function

$$
V\left[x_{t}\right]=\max _{a_{t}}\left\{U\left(a_{t} \mid x_{t}\right)+\sum_{x_{t+1}} P\left(x_{t+1} \mid x_{t}, a_{t}\right) V\left[x_{t+1}\right]\right\} .
$$

This characterization of decision making through time highlights several features that are important for ecosystem management. For example, it includes an explicit accounting of random environmental variation and partial controllability via the probabilities of state transitions. It includes a specification of trade-offs between immediate utility and future valuation through the objective function. Importantly, conservation strategy is seen as state-dependent, in that the action to be taken at a particular time is conditional on the system state at that time. Finally, conservation strategy developed in this manner need not assume stability in either system states or returns. The latter property seems particularly relevant in addressing the resilience-based concern that traditional optimization seeks to hold a system in equilibrium, which ultimately can erode system resilience.

\section{Process uncertainty}

In many, if not most, conservation problems there is uncertainty about the processes driving system dynamics, which can lead to unanticipated outcomes when actions are taken. Process uncertainty can be captured in the above formulation by a set of $K$ process models $P_{k}\left(x_{t+1} \mid \mathrm{x}_{t}, \mathrm{a}_{t}\right)$ incorporating different hypotheses about ecosystem processes. These models provide the probability of transitioning to any system state at time $t+1$, conditioned on system state and management action at time $t$. We can then express a model state $q_{t}$ with elements $q_{t}(k)$ that specify the relative confidence one places in each model. Bayesian updating provides one way to capture observation-based changes in the model state. 
In the presence of structural uncertainty, a value function can be expressed for each model

$$
\begin{aligned}
& V_{k}\left(A_{t} \mid x_{t}\right)= \\
& U\left(a_{t} \mid x_{t}\right)+\sum_{x_{t+1}} P_{k}\left(x_{t+1} \mid x_{t}, a_{t}\right) V_{k}\left(A_{t+1} \mid x_{t+1}\right),
\end{aligned}
$$

and an overall process function averages these value functions over the model state:

$$
\begin{aligned}
& \bar{V}\left(A_{t} \mid x_{t}, q_{t}\right)=\sum_{k} q_{t}(k) V_{k}\left(A_{t} \mid x_{t}\right) \\
& \quad=U\left(a_{t} \mid x_{t}\right)+\sum_{x_{t+1}} \bar{P}\left(x_{t+1} \mid x_{t}, a_{t}, q_{t}\right) \bar{V}\left(A_{t+1} \mid x_{i+1}, q_{t+1}\right) .
\end{aligned}
$$

Optimal decision making under process uncertainty is given by

$$
\begin{aligned}
& \bar{V}\left[x_{t}, q_{t}\right]= \\
& \max _{a_{t}}\left\{U\left(a_{t} \mid x_{t}\right)+\sum_{x_{t+1}} \bar{P}\left(x_{t+1} \mid x_{t}, a_{t}, q_{t}\right) \bar{V}\left[x_{t+1}, q_{t+1}\right]\right\} .
\end{aligned}
$$

A single utility model $U\left(a_{t} \mid \mathrm{x}_{t}\right)$ is used in the above for every process $P_{k}\left(x_{t+1} \mid \mathrm{x}_{t}, \mathrm{a}_{t}\right)$. Alternatively, utility can be model specific, $U_{k}\left(a_{t} \mid \mathrm{x}_{t}\right)$ and expected utility

$$
\bar{U}\left(a_{t} \mid x_{t}, q_{t}\right)=\sum_{k} q_{t}(k) U_{k}\left(a_{t} \mid x_{t}\right)
$$

can be used.

The incorporation of process uncertainty into decision making transforms the decision framework into a Markov belief process that is continuous in model state (Williams 2011b). Thus, decision making is responsive to an evolving model state that itself is given in terms of stochastic system dynamics. Both the strategy and the resulting system behaviors are recognized as being influenced by: (1) the value function; (2) the structure of the system being managed; and (3) the degree and nature of the structural and environmental uncertainties to which it is subjected. With this framework, one can identify an algorithm for adaptive management, with structural uncertainty an influencing factor for the decision-making process (Williams 2001).

\section{Robust decision making}

Yet another implication of resilience thinking for objectives in biodiversity conservation concerns the possibility of "deep" uncertainty about system dynamics (Lempert 2002), along with a risk of highly undesirable outcomes. One such formulation builds on work by Ben-Haim (2006), but involves hypotheses about the structures and processes that guide system dynamics, but lacks even stochastic information about which hypothesis is most appropriate. An approach in this situation is to define a range of possible model states in terms of a "guesstimate", $\widetilde{q}_{t}$, of a model state, and an extent or range of model states given by an uncertainty horizon $\alpha$. An actionspecific robustness function $\hat{\alpha}\left(\alpha \mid V_{c}, \widetilde{q}, x\right)$ specifies an uncertainty horizon for which values exceed some minimum $V_{c}$ :

$$
\begin{aligned}
& \hat{\alpha}\left(a_{t} \mid V_{c}, \tilde{q}_{t}, x_{t}\right)= \\
& \underset{\alpha}{\arg \max }\left[\min _{q_{i} \in R\left(\alpha, \tilde{q}_{i}\right)}\left\{U\left(a_{t} \mid x_{t}\right)+\sum_{x_{t+1}} \bar{P}\left(x_{t+1} \mid x_{t}, a_{t}, q_{t}\right) \bar{V}\left[x_{t+1}, q_{t+1}\right]\right\} \geq V_{c}\right]
\end{aligned}
$$

where $R\left(\alpha, \widetilde{q}_{t}\right)$ consists of model states in a region centered at $\widetilde{q}_{t}$ with extent $\alpha$. Robust decision making with uncertain model state is then defined for a given critical value $V_{c}$ and guesstimate $\widetilde{q}_{t}$ by the selection of the action $a_{t}$ with the largest uncertainty horizon produced by the robustness function (Williams and Johnson 2013).

Advantages of such an approach include the fact that optimization does not rely on the specification of a model state (which may be unavailable or unreliable). Nor does it depend on maximization of expected return; rather, it focuses on achieving a minimum level of performance for as wide a range of model uncertainty as possible. Finally, the approach can be extended to handle deep uncertainty about system states as well as model states (Williams and Johnson 2013). We believe robust objective functions represent an important contribution of resilience thinking to decision-analytic approaches, as well as an explicit response to the widely leveled criticism about optimization leading invariably to decreased resilience.

Uncertain objectives Finally, we note that the objective function and the values it represents may themselves be a source of uncertainty or ambiguity. In some cases there may be an association between values and beliefs about system dynamics, in which case an adaptive approach can simultaneously reveal ecosystem structure and the values that influence its management (Williams 2012). A related framework recognizes a potential for change in values over time, perhaps in response to system changes (White 1984). Although we know of no applications in conservation decision problems, this approach would seem to offer potential for strategy assessment on the assumption that "values are determined in practice by the decisions taken rather than the other way around" (Ludwig 2001). The recognition that linked social and ecological systems are often characterized by twoway feedbacks motivates an exploration of decision-analytic approaches that allow for temporal changes in objectives and how they are weighted. 


\section{Predicting and Monitoring Outcomes}

Beyond the difficulty of formulating biodiversity costs, benefits, and objective functions, a challenge in using a decision-analytic approach is to specify plausible models of system dynamics. Construction of predictive models is an essential aspect of any systematic approach to decision making. A resilience-based perspective, however, emphasizes the difficulty of making even probabilistic predictions because of the need to extrapolate from limited experience, a lack of understanding of mechanisms that can generate extreme events, and the presence of "deep" uncertainty (Walker et al. 2002, Peterson et al. 2003b, Carpenter et al. 2009). Scenario planning has sometimes been advocated as an alternative (Peterson et al. 2003b, Polasky et al. 2011a), even though plausible scenarios can often arise from a (possibly implicit) process of model building (although the models need not be mechanistic nor provide a stochastic structure for scenario futures). For the purposes of decision analysis, we suggest that scenarios should be treated the same as any other potential outcome that might arise from a more traditional approach to modeling. Thus, we view a "model" in its broadest sense as any sort of state and action-dependent prediction or as an algorithm for generating such a prediction.

Bayesian belief networks provide a convenient way in which quantitative and qualitative information can be combined from a wide array of sources to help generate plausible outcomes and explore their consequences (McCann et al. 2006). Bayesian belief networks are increasingly used as metamodeling tools for integrating multiple aspects of ecosystem dynamics (Castelletti and Soncini-Sessa 2007, Barton et al. 2008) and for participatory modeling, which is useful for incorporating diverse knowledge (Walker et al. 2002) and facilitating understanding and trust among stakeholders (Beratan 2007).

One concern in biodiversity conservation is the over-reliance on statistical associations for prediction, given that these associations may be poor predictors of how biodiversity is affected by environmental change. There is a need to focus on the mechanisms and processes that maintain patterns of biodiversity, rather than relying solely on pattern recognition and description (Sarkar et al. 2006, Pressey et al. 2007). These processes include dispersal, local extinction and colonization, species interactions, and range contraction and expansion (Sarkar et al. 2006). Focusing on process dynamics also can be useful in recognizing potential actions for conservation intervention (Richards et al. 1999, Westphal et al. 2003, Tenhumberg et al. 2004, Bogich and Shea 2008, Martin et al. 2011).

We acknowledge the inherent difficulties in modeling ecological processes and recognize that this has been a point of emphasis in resilience thinking. However, a systematic approach to formulating useful models need not depend on a thorough mechanistic understanding or precise parameterization, assuming that uncertainty is acknowledged and treated in a systematic manner (Conroy et al. 2011, Nichols et al. 2011). The critical point is that informed decisions require predictions about the outcomes of potential actions, and these predictions must come from some sort of model of system dynamics. Models are not optional components of decision making, and the challenges associated with modeling and predictions simply cannot be used as reasons to abandon modeling efforts.

As awareness of the need to model ecological processes has grown, so has the acknowledgment that ecosystem models should include thresholds at which ecological systems can undergo abrupt change (Huggett 2005, Lindenmayer and Luck 2005, Groffman 2006, Martin et al. 2009). Such thresholds are frequently viewed as boundaries separating alternative system regimes or basins of attraction (Scheffer et al. 2001, Scheffer and Carpenter 2003, Folke et al. 2004). One important concern for ecosystem management is the loss of resilience as the system state approaches a (perhaps unknown) threshold, and the attendant increase in probability that some disturbance will shift the system to a less desirable stability regime. Another is the possibility of changes in the parameters governing the size and shape of the domains of attraction that make system shifts more or less likely (Beisner et al. 2003). Finally, systems with alternative stable states can exhibit hysteresis, in which a loss of resilience is followed by a system change and thereafter by an increase in resilience so that reversing the change is difficult (Ludwig et al. 1997, Scheffer et al. 2001).

Processes that can generate alternative stable states include overharvesting in the presence of an Allee effect, changes in trophic structure, fragmentation of landscapes, interspecific competition (especially as it applies to invasions by exotics), and transmission of disease (Scheffer 2009). Although a number of researchers have begun to formulate simple models to explore these processes (Ludwig et al. 1997, Scheffer et al. 2001, Carpenter et al. 2002, Scheffer and Carpenter 2003, Scheffer 2009), more needs to be done to develop models that provide practical advice for ecosystem management. In particular, it is sometimes possible to deduce thresholds from process models, as contrasted with the more typical, but less useful, approach of trying to identify them a posteriori using retrospective analyses of time-series data for system state variables. For example, models of metapopulations inhabiting fragmented habitat have been used to develop the concept of "extinction threshold" (Lande 1987, 1988), the fraction of potential habitat patches composed of suitable habitat below which metapopulation extinction is assured. Extinction thresholds are predicted directly from metapopulation vital rates (local probabilities of extinction and colonization) and the key relationships (e.g., between patch area and extinction; patch isolation and colonization) that define those rates. This approach to inference about thresholds provides a strong motivation to develop models of system behavior that 
incorporate those features (e.g., thresholds) into the decision process. This emphasis on process modeling is consistent with our previous recommendation to focus on less descriptive and more mechanistic modeling.

It should be noted that not all regime shifts in ecological systems are catastrophic, and not all systems exhibit pronounced hysteresis (Scheffer et al. 2001, Beisner et al. 2003). In systems where gradual change is the rule, classic decision analysis and its variants remain valuable tools for resource use and conservation. Of course, the trick is to know whether the system of interest has the potential for rapid regime shifts. Where plausible models incorporating or generating multiple regimes can be formulated, decision analysis can also be useful. For example, simple models have been used to demonstrate how optimal management differs under various assumptions about the nature of regime changes (Polasky et al. 2011b). Interestingly, optimal management may be precautionary if a potential regime shift causes changes in system dynamics, and if management affects the probability of a regime shift. With an exogenous probability of a regime shift, the optimal management policy may be unaffected except that it will change in response to the regime shift. The results of Polasky et al. (2011b) provide valuable insights, and we suggest that more of these investigations are warranted.

The implications of potential regime shifts for adaptive management are less clear. Intuition suggests that when resilience is low and the costs associated with undesirable states are high, system probing or experimentation to facilitate learning is unlikely to be prudent (Gunderson 1999, Allen and Gunderson 2011). Indeed, application of adaptive optimization (Williams 1996, 2001) would be expected to produce management strategies that minimize the probability of moving to system states associated with high costs, unless expected learning was sufficient (and the system resilient enough) to recoup the costs over the timeframe of decision making. A productive line of inquiry thus involves understanding how various sources and degrees of uncertainty in the mechanics of regime shifts influence optimal prescriptions for adaptive management. Methods of decision analysis that focus on variability in objective returns and on robust decision making are more likely to be relevant in these cases than classic methods that focus on maximizing expected values.

Modelers also need to become more adept in describing crossscale dynamics, particularly feedbacks between processes operating at different scales that are important to system organization and function (Kerkhoff and Enquist 2007, Cumming and Norberg 2008). In addition, key feedbacks need to be explored between social and natural systems. Indeed, we still have much to learn about how to take a more holistic view of ecosystems and humans, such that the social-ecological system becomes the analytical unit (Janssen and Carpenter 1999, Carpenter 2009, Berkes 2010, Schluter et al. 2012).
Finally, we offer a few comments about monitoring. Monitoring of system state variables and associated vital rates serves four primary roles in decision processes with uncertainty (Yoccoz et al. 2001, Nichols and Williams 2006). Estimates of system state are required: (1) for state-dependent decisions; and (2) for assessing the degree to which objectives are being met. Monitoring also provides (3) a basis for learning, as estimates of key variables are compared against model-based predictions in order to update measures of relative faith in system models (Williams et al. 2002). Finally, monitoring data are used to provide (4) updated or better estimates of key system vital rates. Predictions of thresholds based on system models will be improved by better estimates of the vital rates governing model processes. One response to the potential for thresholds and regime shifts is to monitor the drivers of system change. For example, models producing extinction thresholds (Lande 1987, 1988) emphasize the need for monitoring to assess habitat quality in order to inform models for habitat dynamics (MacKenzie et al. 2011, Miller et al. 2012). The current era of rapid climate change should cause managers to develop modeling and monitoring modules for the dynamics of key environmental drivers affecting managed systems. Monitoring programs for these driver variables will be required in order to track and model system dynamics (Milly et al. 2008, Nichols et al. 2011).

\section{CONCLUSIONS}

Biodiversity conservation is characteristically both dynamic and uncertain. It is dynamic because it depends not on the protection of static biodiversity features or attributes, but on maintenance of the ecological and evolutionary processes that sustain that biodiversity. It is uncertain because ecological systems are inherently stochastic and because any understanding of resource conditions and dynamics is inevitably incomplete. The effectiveness of conservation in sustaining resilient systems thus depends on how well these dynamics and their associated uncertainties can be accounted for in the planning process. To that end, conservation planners increasingly rely on the tools of decision analysis. Although decision-analytic approaches vary considerably, they typically involve (1) properly formulating the decision problem; (2) specifying feasible alternative actions; (3) predicting outcomes attendant to the decision choices; and (4) selecting criteria for evaluating potential outcomes.

Methods of dynamic optimization combine models of system change with objective functions that value present and future consequences of alternative actions. The general conservation problem often involves a temporal sequence of decisions over a long, if not infinite, time horizon, where the optimal action at each decision point depends on time and/or system state. The goal of the analyst is to develop a decision rule or policy that prescribes a management action for each system state at each decision point that is optimal with respect to the objective function. A key advantage of dynamic optimization is its 
ability to produce a feedback policy specifying optimal decisions for "possible" future system states rather than "expected" future states. In practice, this makes optimization appropriate for systems that behave stochastically, absent any assumptions about the system remaining in a desired equilibrium or about the production of a constant stream of resource returns.

In our experience, it is not optimization per se that has been the enemy of resilience, but rather a lack of critical thinking about how to characterize the benefits and costs of conservation to society, how to identify the full suite of potential actions that could be used to enhance the benefits net of costs, and how to represent ways in which systems can change as a result of those actions and other uncontrolled factors. In this regard, we tend to agree with Possingham and Biggs (2012), who suggest that "resilience thinking is one approach to framing a problem-decision science solves it." Thus, we suggest that it is in a careful framing of decision problems that resilience concepts can be operationalized for decision makers. In particular, we believe that objective setting in conservation needs to be more attuned to the dynamics of social-ecological systems and to the possibility of deep uncertainties that underlie the risk of unintended, if not irreversible, outcomes. Resilience thinking also leads to the suggestion that model development should focus more on process than on pattern, on multiple scales of influence, and on phenomena that can create alternative stability regimes.

Finally, we note that a key point of perceived divergence between resilience thinking and decision analysis is focused on the dichotomy between optimizing and diversifying. As Holling (2001) described in his characterization of the adaptive cycles of social-ecological systems:

"It is as if two separate objectives are functioning, but in sequence. The first maximizes production and accumulation; the second maximizes invention and re-assortment. The two objectives cannot be maximized simultaneously but only occur sequentially. And the success in achieving one inexorably sets the stage for its opposite. The adaptive cycle therefore embraces two opposites: growth and stability on the one hand, change and variety on the other."

Certainly the statement that these two objectives cannot be maximized simultaneously is true. However, this does not preclude the possibility of seeking optimal solutions for an objective function that includes elements of both classes of objectives. For example, we might consider an objective to maximize accumulation of some key ecosystem product or service, subject to a constraint that system diversity is maintained above some threshold level, below which system resilience may be reduced. In other cases, systems may be so degraded and threats to resilience may be so great that maximizing diversity and resilience may be the only objective of management. However, in both of these situations, it is possible to develop decision-analytic approaches that should lead to wise decisions. It is our belief that this kind of reconciliation of resilience and decision-analytic approaches can help define the future of conservation practice.

Responses to this article can be read online at: http://www.ecologyandsociety.org/issues/responses. php/5544

\section{Acknowledgments:}

This research was funded by the U.S. Geological Survey, with additional support from the U.S. Fish and Wildlife Service. We thank colleagues C. Allen, L. Ball, P. Fackler, L. Gunderson, E. McDonald-Madden, R. Pawlitz, W. Pine, M. Runge, and C. Walters for useful discussions on this topic. We also thank three anonymous reviewers for suggestions that improved the manuscript. Any use of trade, product, or firm names in this article is for descriptive purposes only and does not imply endorsement by the U.S. Government.

\section{LITERATURE CITED}

Allen, C. R., J. J. Fontaine, K. L. Pope, and A. S. Garmestani. 2011. Adaptive management for a turbulent future. Journal of Environmental Management 92:1339-1345.

Allen, C. R., and L. H. Gunderson. 2011. Pathology and failure in the design and implementation of adaptive management. Journal of Environmental Management 92:1379-1384. http:// dx.doi.org/10.1016/j.jenvman.2010.10.063

Anderson, D. R. 1975. Optimal exploitation strategies for an animal population in a Markovian environment: a theory and an example. Ecology 56:1281-1297. http://dx.doi. org/10.2307/1934697

Armitage, D. R., R. Plummer, F. Berkes, R. I. Arthur, A. T. Charles, I. J. Davidson-Hunt, A. P. Diduck, N. C. Doubleday, D. S. Johnson, M. Marschke, P. McConney, E. W. Pinkerton, and E. K. Wollenburg. 2009. Adaptive co-management for social-ecological complexity. Frontiers in Ecology and the Environment 7:95-102. http://dx.doi.org/10.1890/070089

Arvai, J. L., R. Gregory, and T. L. McDaniels. 2001. Testing a structured decision approach: value-focused thinking for deliberative risk communication. Risk Analysis 21:10651076. http://dx.doi.org/10.1111/0272-4332.216175

Ascher, W. 2001. Coping with complexity and organizational interests in natural resource management. Ecosystems 4:742757. http://dx.doi.org/10.1007/s10021-001-0043-y

Barton, D. N., T. Saloranta, S. J. Moe, H. O. Eggestad, and S. Kuikka. 2008. Bayesian belief networks as a meta-modelling 
tool in integrated river basin management - Pros and cons in evaluating nutrient abatement decisions under uncertainty in a Norwegian river basin. Ecological Economics 66:91-104. http://dx.doi.org/10.1016/j.ecolecon.2008.02.012

Beisner, B. E., D. T. Haydon, and K. Cuddington. 2003. Alternative stable states in ecology. Frontiers in Ecology and the Environment 1:376-382. http://dx.doi.org/10.1890/1540-9295 (2003)001[0376:ASSIE]2.0.CO;2

Ben-Haim, Y. 2006. Info-gap decision theory: decisions under severe uncertainty. Second edition. Academic Press (Elsevier), Oxford, UK,

Beratan, K. K. 2007. A cognition-based view of decision processes in complex social-ecological systems. Ecology and Society 12(1):27. [online] URL: http://www.ecologyandsociety. org/vol12/iss1/art27/

Berkes, F. 2010. Shifting perspectives on resource management: resilience and reconceptualization of "natural resources" and "management". Marine Studies (MAST) 9:1340.

Berkes, F., J. Colding, and C. Folke, editors. 2003. Navigating socio-ecological systems: building resilience for complexity and change. Cambridge University Press, Cambridge, UK.

Biggs, R. 2009. Turning back from the brink: Detecting an impending regime shift in time to avert it. Proceedings of the National Academy of Sciences 106:826-831. http://dx.doi. org/10.1073/pnas.0811729106

Bishop, R. C. 1993. Economic efficiency, sustainability, and bidiversity. Ambio 22:69-73.

Bogich, T., and K. Shea. 2008. A state-dependent model for the optimal management of an invasive metapopulation. Ecological Applications 18:748-761. http://dx.doi. org/10.1890/07-0642.1

Burgman, M. 2005. Risks and decisions for conservation and environmental management. Cambridge University Press, Cambridge, UK. http://dx.doi.org/10.1017/CBO9780511614279

Carpenter, S. R. 2002. Ecological futures: building an ecology of the long now. Ecology 83:2069-2083.

Carpenter, S. R. 2009. Science for managing ecosystem services: beyond the Millennium Ecosystem Assessment. Proceedings of the National Academy of Sciences 106:13051312. http://dx.doi.org/10.1073/pnas.0808772106

Carpenter, S. R., W. A. Brock, and D. Ludwig. 2002. Collapse, learning, and renewal. Pages 173-193 in L. H. Gunderson and C. S. Holling, editors. Panarchy: understanding transformations in human and natural systems. Island Press, Washington, D. C., USA.

Carpenter, S. R., C. Folke, M. Scheffer, and F. Westley. 2009. Resilience: accounting for the noncomputable. Ecology and
Society 14(1):13. [online] URL: http://www.ecologyandsociety. org/vol14/iss1/art13/.

Carpenter, S. R., D. Ludwig, and W. A. Brock. 1999. Management of eutrophication for lakes subject to potentially irreversible change. Ecological Applications 9:751-771. http://dx.doi.org/10.1890/1051-0761(1999)009[0751:MOEFLS] 2.0.CO;2

Castelletti, A., and R. Soncini-Sessa. 2007. Bayesian networks and participatory modelling in water resource management. Environmental Modelling and Software 22:1075-1088. http:// dx.doi.org/10.1016/j.envsoft.2006.06.003

Chapin, F. S. III, G. P. Kofinias, and C. Folke, editors. 2009. Principles of ecosystem stewardship: resilience-based natural resource management in a changing world. Springer, New York, New York, USA.

Clark, C. W. 1971. Economically optimal policies for the utilization of biologically renewable resources. Mathematical Biosciences 12:245-260. http://dx.doi.org/10.1016/0025-5564 (71)90020-4

Clark, C. W., and G. R. Munro. 1978. Renewable resource management and extinction. Journal of Environmental Economics and Management 5:198-205. http://dx.doi. org/10.1016/0095-0696(78)90027-X

Clemen, R. T. 1996. Making hard decisions: an introduction to decision analysis. Second edition. Duxbury Press, Pacific Grove, California, USA.

Conroy, M. J., and J. P. Carroll. 2009. Quantitative conservation of vertebrates. Wiley-Blackwell, Oxford, UK. http://dx.doi.org/10.1002/9781444303155

Conroy, M. J., M. C. Runge, J. D. Nichols, K. W. Stodola, and R. J. Cooper. 2011. Conservation in the face of climate change: the roles of alternative models, monitoring, and adaptation in confronting and reducing uncertainty. Biological Conservation 144:1204-1213. http://dx.doi.org/10.1016/j.biocon.2010.10.019

Cumming, G. S., D. H. M. Cumming, and C. L. Redman. 2006. Scale mismatches in social-ecological systems: causes, consequences, and solutions. Ecology and Society 11(1): 14. [online] URL: http://www.ecologyandsociety.org/vol11/iss1/ art14/

Cumming, G. S., and J. Norberg. 2008. Scale and complex systems. Pages 246-276 in J. Norberg and G. S. Cumming, editors. Complexity theory for a sustainable future. Columbia University Press, New York, New York, USA.

Elmqvist, T., C. Folke, M. Nystrom, G. Peterson, J. Bengtsson, B. Walker, and J. Norberg. 2003. Response diversity, ecosystem change, and resilience. Frontiers in Ecology and the Environment 1:488-494. http://dx.doi.org/10.1890/1540-9295 (2003)001[0488:RDECAR]2.0.CO;2 
Farber, S. C., R. Costanza, and M. A. Wilson. 2002. Economic and ecological concepts for valuing ecosystem services. Ecological Economics 41:375. http://dx.doi.org/10.1016/ S0921-8009(02)00088-5

Fischer, J., G. D. Peterson, T. A. Gardner, L. J. Gordon, I. Fazey, T. Elmqvist, A. Felton, C. Folke, and S. Dovers. 2009. Integrating resilience thinking and optimisation for conservation. Trends in Ecology and Evolution 24:549-554. http://dx.doi.org/10.1016/j.tree.2009.03.020

Folke, C., S. Carpenter, B. Walker, M. Scheffer, T. Elmqvist, L. Gunderson, and C. S. Holling. 2004. Regime shifts, resilience, and biodiversity in ecosystem management. Annual Review of Ecology and Systematics 35:557-581. http://dx.doi. org/10.1146/annurev.ecolsys.35.021103.105711

Freese, C. H. 1998. Wild species as commodities: managing markets and ecosystems for sustainability. Island Press, Washington, D.C., USA.

Gregory, R., L. Failing, M. Harstone, G. Long, T. McDaniels, and D. Ohlson. 2012. Structured decision making: a practical guide to environmental management choices. Wiley, West Sussex, UK. http://dx.doi.org/10.1002/9781444398557

Gregory, R., D. Ohlson, and J. Arvai. 2006. Deconstructing adaptive management: criteria for applications to environmental management. Ecological Applications 16:24112425. http://dx.doi.org/10.1890/1051-0761(2006)016[2411: DAMCFA]2.0.CO;2

Groffman, P. M. 2006. Ecological thresholds: the key to successful environmental management or an important concept with no practical application? Ecosystems 9:1-13.

Gunderson, L. H. 1999. Resilience, flexibility and adaptive management-antidotes for spurious certitude? Conservation Ecology 3(1): 7. [online] URL: http://www.ecologyandsociety. org/vol3/iss 1/art7/

Gunderson, L. H. 2000. Ecological resilience-in theory and application. Annual Review of Ecology and Systematics 31:425-439. http://dx.doi.org/10.1146/annurev.ecolsys.31.1.425

Gunderson, L. H., and C. S. Holling, editors. 2002. Panarchy: understanding transformations in human an natural systems. Island Press, Washington, D.C., USA.

Gunderson, L. H., C. S. Holling, and S. S. Light, editors. 1995. Barriers and bridges to the renewal of ecosystems and institutions. Columbia University Press, New York, New York, USA.

Gunderson, L. H., C. S. Holling, L. Pritchard, Jr., and G. D. Peterson. 2002. Resilience of large-scale resource systems. Pages 3-20 in L. H. Gunderson and L. Pritchard, Jr., editors. Resilience and the behavior of large-scale systems. Island Press, Washington, D.C., USA.
Gunderson, L., G. Peterson, and C. S. Holling. 2008 Practicing adaptive management in complex-ecological systems. Pages 223-245 in J. Norberg and G. S. Cumming, editors. Complexity theory for a sustainable future. Columbia University Press, New York, New York, USA.

Hajkowicz, S., and K. Collins. 2007. A review of multiple criteria analysis for water resource planning and management. Water Resources Management 21:1553-1566. http://dx.doi. org/10.1007/s11269-006-9112-5

Hardin, G. 1968. The tragedy of the commons. Science 162:1243-1248. http://dx.doi.org/10.1126/science.162.3859.1243

Hector, A., and A. Wilby. 2009. Biodiversity and ecosystem functioning. Pages 367-375 in S. A. Levin, editor. The Princeton guide to ecology. Princeton University Press, Princeton, New Jersey, USA.

Hilborn, R., and C. J. Walters. 1992. Quantitative fisheries stock assessment: choice, dynamics, and uncertainty. Chapman and Hall, New York, New York, USA.

Holling, C. S. 1973. Resilience and stability of ecological systems. Annual Review of Ecology and Systematics 4:1-23. http://dx.doi.org/10.1146/annurev.es.04.110173.000245

Holling, C. S. 1992. Cross-scale morphology, geometry, and dynamics of ecosystems. Ecological Monographs 62:447. http://dx.doi.org/10.2307/2937313

Holling, C. S. 2001. Understanding the complexity of economic, ecological, and social systems. Ecosystems 4:390405. http://dx.doi.org/10.1007/s10021-001-0101-5

Holling, C. S. and G. K. Meffe. 1996. Command and control and the pathology of natural resource management. Conservation Biology 10:328-337. http://dx.doi.org/10.1046/ j.1523-1739.1996.10020328.x

Hooper, D. U., F. S. Chapin, III, J. J. Ewel, A. Hector, P. Inchausti, S. Lavorel, J. H. Lawton, D. M. Lodge, M. Lorea, S. Naeem, B. Schmid, H. Setala, A. J. Sysmstad, J. Vandermeer, and D. A. Wardle. 2005. Effects of biodiversity on ecosystem functioning: a consensus of current knowledge. Ecological Monographs 75:35. http://dx.doi.org/10.1890/04-0922

Huang, I. B., J. Keisler, and I. Linkov. 2011. Multi-criteria decision analysis in environmental sciences: ten years of applications and trends. Science of the Total Environment 409:3578-3594. http://dx.doi.org/10.1016/j.scitotenv.2011.06.022

Huggett, A. J. 2005. The concept and utility of 'ecological thresholds' in biodiversity conservation. Biological Conservation 124:301-310. http://dx.doi.org/10.1016/j. biocon.2005.01.037

Janssen, M. A., and S. R. Carpenter. 1999. Managing the resilience of lakes: a multi-agent modeling approach. Ecology 
and Society 3(2):15. [online] URL: http://www.ecologyandsociety. org/vol3/iss2/art15/

Karunanithi, A. T., H. Cabezas, B. R. Frieden, and C. W. Pawlowski. 2008. Detection and assessment of ecosystem regime shifts from Fisher information. Ecology and Society 13(1):22. [online] URL: http://www.ecologyandsociety.org/ vol13/iss 1/art22/

Keefer, D. L., C. W. Kirkwood, and J. L. Corner. 2004. Perspective on decision analysis applications. Decision Analysis 1:4-22. http://dx.doi.org/10.1287/deca.1030.0004

Keene, M., and A. S. Pullin. 2011. Realizing an effectiveness revolution in environmental management. Journal of Environmental Management 92:2130-2135. http://dx.doi. org/10.1016/j.jenvman.2011.03.035

Keeney, R. L. 1982. Decision analysis: an overview. Operations Research 30:803-838. http://dx.doi.org/10.1287/ opre.30.5.803

Keeney, R. L. 1992. Value-focused thinking: a path to creative decisionmaking. Harvard University Press, Cambrdige, Massachusetts, USA.

Kennedy, M. C., E. D. Ford, P. Singleton, M. Finney, and J. K. Agee. 2008. Informed multi-objective decision-making in environmental management using Pareto optimality. Journal of Applied Ecology 45:181-192. http://dx.doi.org/10.1111/ j.1365-2664.2007.01367.x

Kerkhoff, A. J. and B. J. Enquist. 2007. The implications of scaling approaches for understanding resilience and reorganization in ecosystems. Bioscience 57:489-499. http:// dx.doi.org/10.1641/B570606

Kiker, G. A., T. S. Bridges, A. Varghese, T. P. Seager, and I. Linkov. 2005. Application of muticriteria decision analysis in environmental decision makinig. Integrated Environmental Assessment and Management 1:95-108. http://dx.doi. org/10.1897/IEAM 2004a-015.1

Lande, R. 1987. Extinction thresholds in demographic models of territorial populations. The American Naturalist 130:624635. http://dx.doi.org/10.1086/284734

Lande, R. 1988. Demographic models of the northern spotted owl (Strix occidentalis caurina). Oecologia 75:601-607. http://dx.doi.org/10.1007/BF00776426

Lebel, L., J. M. Anderies, B. Campbell, C. Folke, S. HatfieldDodds, T. P. Hughs, and J. Wilson. 2006. Governance and the capacity to manage resilience in regional socio-ecological systems. Ecology and Society 11(1):19. [online] URL: http:// www.ecologyandsociety.org/vol11/iss1/art19/

Lee, K. N. 1993. Compass and gyroscope: integrating science and politics for the environment. Island Press, Washington, D. C., USA.
Lee, K. N. 1999. Appraising adaptive management. Conservation Ecology 3(2): 13. [online] URL: http://www. ecologyandsociety.org/vol3/iss2/art3/ http://dx.doi. org/10.1201/9781420042597.sec1

Lempert, R. J. 2002. A new decision sciences for complex systems. Proceedings of the National Academy of Sciences 99:7309-7313. http://dx.doi.org/10.1073/pnas.082081699

Levin, S. A. 1992. The problem of pattern and scale in ecology. Ecology 73:1943-1967. http://dx.doi.org/10.2307/1941447

Levin, S. 1999. Fragile dominion: complexity and the commons. Perseus Books, Reading, Massachusetts, USA.

Levin, S. A. 2000. Multiple scales and the maintenance of biodiversity. Ecosystems 3:498-506. http://dx.doi.org/10.1007/ $\underline{\text { s100210000044 }}$

Lindenmayer, D. B. and G. Luck. 2005. Synthesis: thresholds in conservation and management. Biological Conservation 124:351-354. http://dx.doi.org/10.1016/j.biocon.2005.01.041

Linkov, I., F. K. Satterstrom, G. A. Kiker, T. S. Bridges, S. L. Benjamin, and D. A. Belluck. 2006. From optimization to adaptation: shifting paradigms in environmental management and their application to remedial decisions. Integrated Environmental Assessment and Management 2:92-98. http:// dx.doi.org/10.1002/ieam.5630020116

Ludwig, D. 2001. The era of management is over. Ecosystems 4:758-764. http://dx.doi.org/10.1007/s10021-001-0044-x

Ludwig, D., R. Hilborn, and C. Walters. 1993. Uncertainty, resource exploitation, and conservation: lessons from history. Science 260:17, 36. http://dx.doi.org/10.1126/science.260.5104.17

Ludwig, D., B. Walker, and C. S. Holling. 1997. Sustainability, stability, and resilience. Conservation Ecology 1(1): 7. [online] URL: http://www.ecologyandsociety.org/vol1/iss1/ $\underline{\operatorname{art} 71}$

MacKenzie, D. I., L. L. Bailey, J. E. Hines, and J. D. Nichols. 2011. An integrated model of habitat and species occurrence dynamics. Methods in Ecology and Evolution 2:612-622. http://dx.doi.org/10.1111/j.2041-210X.2011.00110.x

Margules, C. R., and R. L. Pressey. 2000. Systematic conservation planning. Nature 405:243-253. http://dx.doi. org/10.1038/35012251

Martin, J., P. L. Fackler, J. D. Nichols, M. C. Runge, C. L. McIntyre, B. C. Lubow, M. C. McCluskie, and J. A. Schmutz. 2011. An adaptive-management framework for optimal control of hiking near golden eagle nests in Denali National Park. Conservation Biology 25:316-323.

Martin, J., M. C. Runge, J. D. Nichols, B. C. Lubow, and W. L. Kendall. 2009. Structured decision making as a conceptual framework to identify thresholds for conservation and 
management. Ecological Applications 19:1079-1090. http:// dx.doi.org/10.1890/08-0255.1

McCann, R. K., B. G. Marcot, and R. Ellis. 2006. Bayesian belief networks: applications in ecology and natural resource management. Canadian Journal of Fisheries and Aquatic Sciences 36:3053-3062.

McCarthy, M. A., and H. P. Possingham. 2007. Active adaptive management for conservation. Conservation Biology 21:956-963. http://dx.doi.org/10.1111/j.1523-1739.2007.00677. $\underline{\mathrm{X}}$

McFadden, J. E., T. L. Hiller, and A. J. Tyre. 2011. Evaluating the efficacy of adaptive management approaches: is there a formula for success? Journal of Environmental Management 92:1354-1359.

Meir, E., S. Andelman, and H. P. Possingham. 2004. Does conservation planning matter in a dynamic and uncertain world? Ecology Letters 7:615-622.

Mendoza, G. A., and H. Martins. 2006. Multi-criteria decision analysis in natural resource management: a critical review of methods and new modelling paradigms. Forest Ecology and Management 230:1-22. http://dx.doi.org/10.1016/j. foreco.2006.03.023

Meyer, P. B. 1976. Optimization and the sacrifice of diversity to efficiency. Journal of Economic Issues 10:328-349.

Miller, D. A. W., C. S. Brehme, J. E. Hines, J. D. Nichols, and R. N. Fisher. 2012. Joint estimation of habitat dynamics and species interactions; disturbance reduces co-occurrence of non-native predators with an endangered toad. Journal of Animal Ecology 81: 1288-1297. http://dx.doi.org/10.1111/ j.1365-2656.2012.02001.x

Milly, P. C. D., J. Betancourt, M. Falkenmark, R. M. Hirsch, Z. W. Kundzewicz, D. P. Lettenmaier, and R. J. Stouffer. 2008. Stationarity is dead: whither water management? Science 319:573-574.

Moilanen, A., K. A. Wilson, and H. P. Possingham. 2009. Spatial conservation prioritization: quantitative methods and computational tools. Oxford University Press, Oxford, UK.

Moir, W. H., and W. M. Block. 2001. Adaptive management on public lands in the United States: comitment or rhetoric? Environmental Management 28:141-148.

Murdoch, W., S. Polasky, K. A. Wilson, H. P. Possingham, P. Kareiva, and R. Shaw. 2007. Maximizing return on investment in conservation. Biological Conservation 139:375-388. http://dx.doi.org/10.1016/j.biocon.2007.07.011

Naeem, S. 2002. Ecosystem consequences of biodiversity loss: the evolution of a paradigm. Ecology 83:1537-1552. http:// dx.doi.org/10.1890/0012-9658(2002)083[1537:ECOBLT]2.0. $\underline{\mathrm{CO} ; 2}$
Naidoo, R., A. Balmford, P. J. Ferraro, S. Polasky, T. H Ricketts, and M. Rouget. 2006. Integrating economic costs into conservation planning. Trends in Ecology and Evolution 21:681-687. http://dx.doi.org/10.1016/j.tree.2006.10.003

Naidoo, R., and T. H. Ricketts. 2006. Mapping the economic costs and benefits of conservation. PLoS Biology 4:21532164. http://dx.doi.org/10.1371/journal.pbio.0040360

Nichols, J. D., M. D. Koneff, P. J. Heglund, M. G. Knutson, M. E. Seamans, J. E. Lyons, J. M. Morton, M. T. Jones, G. S. Boomer, and B. K. Williams. 2011. Climate change, uncertainty, and natural resource management. The Journal of Wildlife Management 75:6-18. http://dx.doi.org/10.1002/ jwmg.33

Nichols, J. D., and B. K. Williams. 2006. Monitoring for conservation. Trends in Ecology and Evolution 21:668-673. http://dx.doi.org/10.1016/j.tree.2006.08.007

Norberg, J., J. Wilson, B. Walker, and E. Ostrum. 2008. Diversity and resilience of socio-ecological systems. Pages 46-79 in J. Norberg and G. S. Cumming, editors. Complexity theory for a sustainable future. Columbia University Press, New York, New York, USA.

Norton, B. G. 2005. Sustainability: a philosophy of adaptive ecosystem management. University of Chicago Press, Chicago, Illinois, USA. http://dx.doi.org/10.7208/

chicago/9780226595221.001.0001

Nunes, P. A. L. D., and J. C. J. M. van den Bergh. 2001. Economic valuation of biodiversity: sense or nonsense? Ecological Economics 39:203.

Peterson, G., C. R. Allen, and C. S. Holling. 1998. Ecological resilience, biodiversity, and scale. Ecosystems 1:6-18. http:// dx.doi.org/10.1007/s100219900002

Peterson, G. D., S. R. Carpenter, and W. A. Brock. 2003a. Uncertainty and the management of multistate systems: an apparently rational route to collapse. Ecology 84:1403-1411.

Peterson, G. D., G. S. Cumming, and S. R. Carpenter. 2003b. Scenario planning: a tool for conservation in an uncertain world. Conservation Biology 17:358-366.

Poiani, K. A., B. D. Richter, M. G. Anderson, and H. E. Richter. 2000. Biodiversity conservation at multiple scales: functional sites, landscapes, and networks. Bioscience 50:133-146. http://dx.doi.org/10.1641/0006-3568(2000)050 [0133:BCAMSF]2.3.CO;2

Polasky, S. 2008. Why conservation planning needs socioeconomic data. Proceedings of the National Academy of Science 105:6505-6506. http://dx.doi.org/10.1073/pnas.0802815105

Polasky, S., S. R. Carpenter, C. Folke, and B. Keeler. 2011 a. Decision-making under great uncertainty: environmental 
management in an era of global change. Trends in Ecology and Evolution 26:398-404.

Polasky, S., A. de Zeeuw, and F. Wagener. 2011b. Optimal management with potential regime shifts. Journal of Environmental Economics and Management 62:229-240.

Polasky, S., E. Nelson, J. Camm, B. Csuti, P. Fackler, E. Lonsdorf, C. Montgomery, D. White, J. Arthur, B. GarberYonts, R. Haight, J. Kagan, A. Starfield, and C. Tobalske. 2008. Where to put things? Spatial land management to sustain biodiversity and economic returns. Biological Conservation 141:1505-1524. http://dx.doi.org/10.1016/j.biocon.2008.03.022

Polasky, S., E. Nelson, E. Lonsdorf, P. Fackler, and A. Starfield. 2005. Conserving species in a working landscape: land use with biological and economic objectives. Ecological Applications 15:1387-1401. http://dx.doi.org/10.1890/03-5423

Possingham, H. 2001. The business of biodiversity: applying decision theory principles to nature conservation. Pages 1-37 in D. Yencken, editor. The Tela papers. Australian Conservation Foundation, Melbourne, Australia.

Possingham, H., and D. Biggs. 2012. Resilience thinking vesus decision theory? Decision Point 62:4-5.

Pressey, R. L., M. Cabeza, M. E. Watts, R. M. Cowling, and K. A. Wilson. 2007. Conservation planning in a changing world. Trends in Ecology and Evolution 22:583-592. http:// dx.doi.org/10.1016/j.tree.2007.10.001

Richards, S. A., H. P. Possingham, and J. Tizard. 1999. Optimal fire management for maintaining community diversity. Ecological Applications 9:880-892. http://dx.doi. org/10.1890/1051-0761(1999)009[0880:OFMFMC]2.0.CO;2

Sarkar, S. and C. Margules. 2002. Operationalizing biodiversity for conservation planning. Journal of Biosciences 27 (Suppl. 2):299-308. http://dx.doi.org/10.1007/BF02704961

Sarkar, S., R. L. Pressey, D. P. Faith, C. R. Margules, T. Fuller, D. M. Stoms, A. Moffett, K. A. Wilson, K. J. Williams, P. H. Williams, and S. Andelman. 2006. Biodiversity conservation planning tools: present status and challenges for the future. Annual Review of Environment and Resources 31:123-159. http://dx.doi.org/10.1146/annurev.energy.31.042606.085844

Scheffer, M. 2009. Critical transitions in nature and society. Princeton University Press, Princeton, New Jersey, USA.

Scheffer, M., J. Bascompte, W. A. Brock, V. Brovkin, S. R. Carpenter, V. Dakos, Held, H., E. H. van Ness, M. Rietkerk, and G. Sugihara. 2009. Early-warning signals for critical transitions. Nature 461:53-59. http://dx.doi.org/10.1038/ $\underline{\text { nature } 08227}$

Scheffer, M. and S. R. Carpenter. 2003. Catastrophic regime shifts in ecosystems: linking theory to observation. Trends in
Ecology and Evolution 18:648-656. http://dx.doi.org/10.1016/ j.tree.2003.09.002

Scheffer, M., S. Carpenter, J. A. Foley, C. Folke, and B. Walker. 2001. Catastrophic shifts in ecosystems. Nature 413:591-596. http://dx.doi.org/10.1038/35098000

Schluter, M., R. R. J. McAllister, R. Arlinghaus, N. Bunnefeld, K. Eisenack, F. Holker, E. J. Milner-Gulland, and B. Muller. 2012. New horizons for managing the environment: a review of coupled social-ecological systems modeling. Natural Resource Modeling 25:219-272. http://dx.doi.org/10.1111/ j.1939-7445.2011.00108.x

Schreiber, E. S. G., A. R. Bearlin, S. J. Nicol, and C. R. Todd. 2004. Adaptive management: a synthesis of current understanding and effective application. Ecological Management and Restoration 5:177-182. http://dx.doi. org/10.1111/j.1442-8903.2004.00206.X

Skinner, D. C. 2009. Introduction to decision analysis. Probabilistic Publishing, Sugar Land, Texas, USA.

Susskind, L., A. E. Camacho, and T. Schenk. 2010. Collaborative planning and adaptive management in Glen Canyon: a cautionary tale. Columbia Journal of Environmental Law 35:1-54.

Tenhumberg, B., A. J. Tyre, K. Shea, and H. Possingham. 2004. Linking wild and captive populations to maximize species persistence: optimal translocation strategies. Conservation Biology 18:1304-1314. http://dx.doi.org/10.1111/ j.1523-1739.2004.00246.x

Tilman, D. 1999. The ecological consequences of changes in biodiversity: a search for general principles. Ecology 80:14551474.

Tonn, B., M. English, and C. Travis. 2000. A framework for understanding and improving environmental decision making. Journal of Environmental Planning and Management 43:163183. http://dx.doi.org/10.1080/09640560010658

Walker, B. H. 1992. Biodiversity and ecological redundancy. Conservation Biology 6:18-23. http://dx.doi.org/10.1046/ j.1523-1739.1992.610018.x

Walker, B. 1995. Conserving biological diversity through ecosystem resilience. Conservation Biology 9:747-752. http:// dx.doi.org/10.1046/j.1523-1739.1995.09040747.x

Walker, B., S. Carpenter, J. Anderies, N. Abel, G. Cumming, M. Janssen, L. Lebel, J. Norberg, G. D. Peterson, and R. Pritchard. 2002. Resilience management in socio-ecological systems: a working hypothesis for a participatory approach. Conservation Ecology 16(1):14. [online] URL: http://www. ecologyandsociety.org/vol6/iss1/art14/ 
Walker, B., C. S. Holling, S. R. Carpenter, and A. Kinzig. 2004. Resilience, adaptability and transformability in socialecological systems. Ecology and Society 9(2): 5. [online] URL: http://www.ecologyandsociety.org/vol9/iss2/art5/

Walker, B., and D. Salt. 2006. Resilience thinking: sustaining ecosystems and people in a changing world. Island Press, Washington, D.C., USA.

Walters, C. J. 1986. Adaptive management of renewable resources. MacMillan Publishing Co., New York, New York, USA.

Westphal, M. I., M. Pickett, W. M. Getz, and H. P. Possingham. 2003. The use of stochastic dynamic programming in optimal landscape reconstruction for metapopulations. Ecological Applications 13:543-555. http:// dx.doi.org/10.1890/1051-0761(2003)013[0543:TUOSDP]2.0. $\underline{\mathrm{CO} ; 2}$

White, C. C. III. 1984. Sequential decision making under uncertain future preferences. Operations Research 32:148168. http://dx.doi.org/10.1287/opre.32.1.148

Whittaker, R. J., M. B. Araujo, P. Jepson, R. J. Laddle, J. E. M. Watson, and K. J. Willis. 2005. Conservation biogeography: assessment and prospect. Diversity and Distributions 11:3-23. http://dx.doi.org/10.1111/ j.1366-9516.2005.00143.x

Williams, B. K. 1989. Review of dynamic optimization methods in renewable natural resource management. Natural Resource Modeling 3:137-216.

Williams, B. K. 1996. Adaptive optimization of renewable natural resources: solution algorithms and a computer program. Ecological Modelling 93:101-111. http://dx.doi. org/10.1016/0304-3800(95)00217-0

Williams, B. K. 2001. Uncertainty, learning, and the optimal management of wildlife. Environmental and Ecological Statistics 8:269-288. http://dx.doi.org/10.1023/A:1011395725123

Williams, B. K. 2011a. Adaptive management of natural resources-framework and issues. Journal of Environmental Management 92:1346-1353.

Williams, B. K. 2011b. Resolving structural uncertainty in natural resources management using POMDP approaches. Ecological Modelling 222:1092-1102.

Williams, B. K. 2012. Reducing uncertainty about objective functions in adaptive management. Ecological Modelling 225:61-65. http://dx.doi.org/10.1016/j.ecolmodel.2011.11.009

Williams, B. K., and F. A. Johnson. 2013. Confronting dynamics and uncertainty in optimal decision making for conservation. Environmental Research Letters 8: 025004. http://dx.doi.org/10.1088/1748-9326/8/2/025004
Williams, B. K., J. D. Nichols, and M. J. Conroy. 2002. Analysis and management of animal populations. Academic Press, San Diego, California, USA.

Willis, K. J., and R. J. Whittaker. 2002. Species diversity: scale matters. Science 295:1245-1248. http://dx.doi.org/10.1126/ science. 1067335

Wilson, H. B., L. N. Joseph, A. L. Moores, and H. P. Possingham. 2011. When should we save the most endangered species? Ecology Letters 14:886-890.

Wilson, J. 2006. "New" and "old" modes of environmental governance: the evolution of the North American waterfowl bird policy regime. Western Political Science Association Conference, Albuquerque, New Mexico, USA.

Wilson, K. A., M. F. McBride, M. Bode, and H. P. Possingham. 2006. Prioritizing global conservation efforts. Nature 440:337-340. http://dx.doi.org/10.1038/nature04366

Wilson, K. A., E. C. Underwood, S. A. Morrison, K. R. Klausmeyer, W. W. Murdoch, B. Reyers, G. Wardell-Johnson, P. A. Marquet, P. W. Rundel, M. F. McBride, R. L. Pressey, M. Bode, J. M. Hoekstra, S. Andelman, M. Looker, C. Rondinini, P. Kareiva, M. R. Shaw, and H. P. Possingham. 2007. Conserving biodiversity efficiently: what to do, where, and when. PLoS Biology 5:e223. http://dx.doi.org/10.1371/ journal.pbio.0050223

Yoccoz, N. G., J. D. Nichols, and T. Boulinier. 2001. Monitoring of biological diversity in space and time. Trends in Ecology and Evolution 16:446-453. http://dx.doi. org/10.1016/S0169-5347(01)02205-4 